\title{
Editorial
}

\section{Approaches to Latino/a identity formation}

Latino Studies (2009) 7, 165-166. doi:10.1057/lst.2009.16

"Who am I?" is a question often posed by Latino/a and non-Latino/a students alike, on campuses across the nation - partly as a result of their transition to adulthood, and partly because they develop an awareness of the consequences of the notion of difference for their lives, in terms of their social, ethnic and racial backgrounds and gendered experiences. Among Latino/as, the question is often made more complex because of their biculturalism and bilingualism, in a society that has long made Latino/as' contributions invisible and denied their distinct cultural belonging.

This issue presents different approaches to Latino/a identity formation, through articles that directly or indirectly contribute to theorize Latino/a cultural identity, and to understand some of the ways in which racial and ethnic relations in US society can impact on Latino/as' individual sense of self, their interactions, and the public policies and institutions that shape their experiences and affect their lives in this country.

The question of "Who am I?" leads Bernardo Canteñs to take as his point of departure the idea that cultural identity is "intrinsic to our selfhood." His aim is to propose a metaphysical theory of cultural identity by identifying the criteria for determining what actually constitutes a cultural group. Canteñs first evaluates the models for determining cultural identity as well as various metaphysical views of group identity in the works of three philosophers of Latino/a identity - Linda Martín Alcoff, J. Angelo Corlett and Jorge J.E. Gracia. His analysis of their models leads Canteñs to adopt an approach to cultural identity that is grounded in Darwin's view of "the order of nature." Aiming to avoid "the extreme views of 'essentialism' and 'eliminativism'," he illustrates the ways that this perspective can provide a paradigm for better understanding both cultural identity as well as ethnic identity.

Jessica Tovar and Cynthia Feliciano draw on their survey and qualitative research to assess how and why ethnic self-identification changes through time - specifically addressing this issue from the perspective of the children of Mexican immigrants in Southern California. In so doing, they highlight the significance of social and political contexts, generational status, and transnational and educational experiences, in terms of their impact on perceptions of changes in ethnic self-identification.

Undoubtedly, schools play an essential role in debates on identity formation and ethnic and race relations. Regardless of President Obama's victory and the subsequent "end-of-racism" proclamations in US society, the extent of school (re)segregation today, and the accompanying racial and ethnic issues 
it continues to raise, necessarily still dominate current efforts toward the construction of a just society. Hence, conscious efforts to adopt school integration plans, like their consequences for majority/minority relations, continue to underlie the development of individual, social and cultural identities in the United States. Bradley Bartels and Rubén Donato discuss the economic implications of attempts by school districts to achieve "race-conscious economic integration," by redrawing school attendance zones that include racially segregated neighborhoods. The authors' analysis is grounded in a case study of a district in Northern Colorado that redrew its attendance zone because it constructed a new middle school in an affluent White neighborhood. Their discussion leads them to conclude that "School authorities need to be cognizant of the limits and possibilities of race-conscious economic integration plans and mindful of their potential adverse effects."

Considered together, the varied premises of this issue's articles - whether grounded in the need for a definition of cultural identity, the exploration of selfidentification among young Latino/as, or the policies and institutions that emphasize school integration as a means of addressing the economic and racial issues that ultimately impact on Latino/as experiences - illustrate the diversity of approaches to the concept of identity formation. Moreover, regardless of whether this elusive concept is the central concern of research on Latino/as, the realities of race and ethnicity in US society, as these authors' work suggests, continue to be significant for understanding the issues and processes involved in constructing Latino/as' identity and their integration into the society.

In this issue, we also publish our annual section, Reflexiones Pedagógicas. This year, we invited Professor Mari Castaneda to organize a special section on teaching Latino/a studies in predominantly white Universities. In the context of our focus on Latino/a identity, these pedagogical essays are particularly useful, for all of them discuss the extent to which it is possible - and essential - to convey the specificities of Latino/a identities and culture, in ways that neither exoticize nor homogenize the experiences of Latino/as in the US.

The need to construct a multicultural society grounded in the empirical acknowledgement (rather than the theoretical abstractions) of the ways that ethnic and racial differences structure individual experiences is increasingly recognized in educational settings across the country. In these Reflexiones Pedagógicas, professors in colleges and Universities in the North East, describe their experiences teaching in predominantly non-Latino/a contexts, and pinpoint some of the issues involved in integrating cross-cultural issues in their classroom pedagogy. Collectively, their articles suggest new ways of deepening the discussion on Latino identity formation in the United States.

Saludos!

Suzanne Oboler

John Jay College of Criminal Justice, City University of New York, NY. 